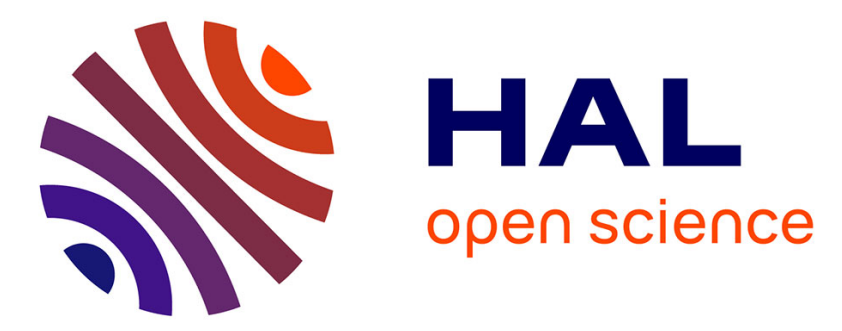

\title{
Free and Open-Source Automated 3-D Microscope
} Bas Wijnen, Emily E Petersen, Emily J Hunt, Joshua Pearce

\section{To cite this version:}

Bas Wijnen, Emily E Petersen, Emily J Hunt, Joshua Pearce. Free and Open-Source Automated 3-D Microscope. Journal of Microscopy, 2016, 264 (2), pp.238-246. 10.1111/jmi.12433 . hal-02113495

\section{HAL Id: hal-02113495 https://hal.science/hal-02113495}

Submitted on 28 Apr 2019

HAL is a multi-disciplinary open access archive for the deposit and dissemination of scientific research documents, whether they are published or not. The documents may come from teaching and research institutions in France or abroad, or from public or private research centers.
L'archive ouverte pluridisciplinaire HAL, est destinée au dépôt et à la diffusion de documents scientifiques de niveau recherche, publiés ou non, émanant des établissements d'enseignement et de recherche français ou étrangers, des laboratoires publics ou privés. 


\title{
Free and Open Source Automated 3-D Microscope
}

\author{
Bas Wijnen ${ }^{1}$, Emily E. Petersen ${ }^{1}$, Emily J. Hunt ${ }^{1}$, and Joshua M. Pearce ${ }^{1,2^{*}}$
}

1 Department of Materials Science \& Engineering, Michigan Technological University, Houghton, MI, USA

2 Department of Electrical \& Computer Engineering, Michigan Technological University, Houghton, MI, USA

* Corresponding author: 1400 Townsend Drive Houghton, MI 49931, USA, E-Mail: pearce@mtu.edu; Tel.: +1-906-487-1466

\begin{abstract}
Open-source technology not only has facilitated the expansion of the greater research community, but by lowering costs it has encouraged innovation and customizable design. The field of automated microscopy has continued to be a challenge in accessibility due the expense and inflexible, non-interchangeable stages. This paper presents a low-cost, open source microscope 3-D stage. A RepRap 3-D printer was converted to an optical microscope equipped with a customized, 3-D printed holder for a USB microscope. Precision measurements were determined to have an average error of $10 \mu \mathrm{m}$ at the maximum speed and $27 \mu \mathrm{m}$ at the minimum recorded speed. Accuracy tests yielded an error of $0.15 \%$. The machine is a true $3-\mathrm{D}$ stage and thus able to operate with USB microscopes or conventional desktop microscopes. It is larger than all commercial alternatives, and is thus capable of high depth images over unprecedented areas and complex geometries. The repeatibility is below 2-D microscope stages, but testing shows that it is adequate for the majority of scientific applications. The open source microscope stage costs less than 3\% to $9 \%$ of the closest proprietary commercial stages. This extreme affordability vastly improves accessibility for 3-D microscopy throughout the world.
\end{abstract}

Keywords: microscope; optics; imaging; 3-D microscope; stage; open hardware

\section{Introduction}

The free and open source software (FOSS) community has demonstrated that by facilitating participation in technical projects with little to no startup costs, meaningful contributions from the community can be made (Raymond, 1999; Lakhani \& Von Hippel, 2003; Weber, 2004). FOSS is also referred to as libre software to emphasize development founded on freedom as opposed to price. This scaled collaboration results in superior design with lower associated cost due to the continuous improvement in software code, thereby making it more robust and innovative (Raymond, 1999; Soderberg, 2008). FOSS has shown to be more reliable and relevant to users as they are co-developers (Kogut \& Metiu, 2001). For instance, 97\% of the world's supercomputers operate on FOSS GNU/Linux (Vaughan-Nichols, 2014). The success of open source software has provided an alternative to expensive and proprietary systems by allowing for reduced research and development costs (Lakhani \& Von Hippel, 2003) as well as more flexible design (Mockus et al., 2002). Open source development outside of purely software has established a particularly vibrant 3-D printing community around the self-replicating rapid protoyper (RepRap) 3-D printer family (Jones et al., 2001; Sells et al., 2010; Woelfe et al., 2011; Bowyer, 2014; Rundle, 2014). FOSS and open hardware design can be combined with RepRap 3-D printing for distributed digital fabrication of low-cost scientific equipment (Pearce, 2012; Baden et al., 2015) including: colorimeters (Anzalone et al., 2013a), nephelometers (Wijnen et al., 2013), turbidimeters (Kelley et al., 2014), liquid autosampers (Carvalho \& Eyre, 2013), microfluid handlers (Da Costa et al., 2014), biotechnological and chemical labware (Lucking et al., 2014; Gross et al., 2014; Su et al, 2014), mass spectroscopy equipment 
(Malonado-Toress et al., 2014), automated sensing arrays (Wittbrodt et al., 2014), phasor measurement units (Laverty et al., 2013), optics and optical system components (Zhang et al., 2013), DNA nanotechnology lab tools (Damase et al., 2015) and compatible components for medical apparatuses (Hermann et al., 2014). The open sharing of digital design has reduced capital cost to an unprecedented 90-99\% decrease from the cost of conventional equipment (Pearce, 2014a,b). The lateral scaling of shared design has created substantial value (Pearce, 2015) resulting in hundreds and even thousands of percent return on investment for science funders (Pearce, 2016). This open source development methodology holds some promise for improving accessibility of automated microscopy.

The field of automated microscopy faces a number of challenges in becoming more accessible to those without extensive training or funding. Automated microscope stages are typically costly and limited in use due to the lack of adaptability. However, the quality of digital sensors has significantly improved, combined with a decrease in cost, which make the option of using an open source approach technically possible. Furthermore, the associated software, traditionally a proprietary component of automated microscopy, has begun to transition into open source programs such as ImageJ and iMSRC. Not only has automated microscopy aided in improving the reproducibility of results in the greater research community, but it has allowed more individuals to learn proper operation and perform more complex analysis techniques.

Although advances have been made in creating inexpensive microscopes (Cybulski et al., 2014; University of Cambridge, 2016), established automated microscope models remain essential for scientific research such as the detection of tumor cells in bone marrow (Borgen et al., 2001), pollen analysis (Holdaway, 2004), and there-dimensional examination of cellular structures and macromolecules (Mastronarde, 2005). The cost of sophisticated instrumentation is in the thousands or tens of thousands of dollars, creating a significant barrier to joining the scientific community in those fields. Decreasing that cost not only enables scientists with limited funding and resources to perform higher quality research, but it allows everyone in the scientific community to allocate funding to other needs (Pearce, 2014). Open source space has provided a new platform of innovation for automated microscopy (University of Cambridge, 2016). By taking advantage of existing tools such as Raspberry $\mathrm{Pi}$, Arduino controllers, 3-D printed parts and beam structure, advancements can be made toward creating a generic system of ultimately customizable automated microscopes (University of Cambridge, 2016). In addition, the RepRap 3-D printer has been shown to be a practical low-cost scientific 3-D stage (Zhang et al., 2016).

This study looks to build on the ongoing developments in automated microscopy in the open source community. A RepRap 3-D printer was converted to a 3-D microscope, and as this study is released as free and open source, all interfaces are readily available and can be easily integrated into new or existing experimental setups. The 3-D microscope is validated using experiments to compare its accuracy and precision to commercial alternatives. In addition, the system is demonstrated for photo stitching and focus stacking. Finally, the open source 3-D microscope is compared to proprietary commercial tools and the results are presented and discussed.

\section{Background}

Automated microscope stages allow for examination of multiple specimens by facilitating stage movement in the $\mathrm{x}, \mathrm{y}$ and $\mathrm{z}$ directions. Stages are typically for either upright or inverted microscopes, however as they are not adaptable for both and are frequently designed for specific microscope models, they have limited practical use. Stage sizes range from $135 \mathrm{~mm}$ x $85 \mathrm{~mm}$ to $275 \mathrm{~mm}$ x175 mm, and both repeatability and reproducibility are less than one micron. Stages of these parameters, however, can cost the user anywhere from US\$4,900 (ASR Series) to US\$16,000 (Leica 
Microsystems). This cost does not include additional costs associated with the software package and hardware required to mount the stage on the microscope.

The field of automated microscopy has seen a number of recent developments, in part due to the advancement of digital sensors. The increase in quality coupled with the decrease in cost has played a significant role. Automated microscopy contributes in a meaningful way to the greater research community by making results more reproducible (Riedl et al., 2015), enabling less-trained operators to obtain quality measurements (D’Ambrosio et al., 2015), and facilitating more complex analytical methods such as neural-based pattern detection (Schneider et al., 2015).

While the software used to control automated microscopes and analyze measurements has traditionally been proprietary, free and open source options have since matured. iMSRCS is a software developed in recent years that combines flexibility with ease of use in order to enable various applications (Carro et al., 2015). ImageJ is another software tool that allows for automation of experiments with the help of scripts and plugins (Schindelin et al., 2015). It can also be combined with MicroManager to control an automated microscope (Micro-manager, 2016).

\section{Experimental}

A delta RepRap derived from the MOST delta, called the Athena, is robot with exchangeable tools that can be used as a 3-D printer (Anzalone et al., 2013b; Anzalone et al., 2015). Smaller tools can be mounted on the end effector, enabling movement over a static object. The platform can also be mounted to the end effector, allowing for bigger tools such as a metal welder to be mounted in a stationary position on top of the machine (Anzalone et al., 2013b). For use in microscopy, a small USB microscope can be mounted as a mobile tool or a heavy microscope can be mounted as a stationary tool.

The RepRap was controlled using Franklin (Franklin, 2016) which allows external scripts to control the machine, thus allowing integration of the microscope in a larger experimental setup (Wijnen et al., 2016). For example, the microscope can be moved vertically to keep a moving object in focus, or horizontally to keep it in the view. A script that is available at (Franklin, 2016) enables a game controller to move the tool. This allows the user to control the microscope without looking at the keyboard or screen, instead providing a full screen view of the microscope output. Four positions can be stored and linked to buttons on the game controller for ease of revisiting.

Several experiments were performed in order to demonstrate the capabilities of the device. To test the precision of the positioning for long moves, a calibration slide with a dot of $70 \mu \mathrm{m}$ diameter was positioned at two positions on the platform; one in the center at $(0,0)$ and one at $(0,100)$. The microscope was then moved to a different location at the edge of the range before being repositioned to the calibration dot. The position of the dot in the microscope image was recorded each time. The measurement was performed using 36 points on the edge of the range, which were equally spaced with a spacing of 10 degrees. Every position was measured at three speeds: 2, 20 and $60 \mathrm{~mm} / \mathrm{s}$.

To test the precision of the positioning for short moves, the microscope was focused on the dot and moved over a circle with a radius of $50 \mu \mathrm{m}$ in steps of 10 degrees. These steps were small enough to ensure that the dot remained in view of the microscope. The dot position was recorded after every 
move, and compared to the target values. A statistical analysis was then performed on the data. For each recorded image, the position of the dot was determined. For each dot, the distance and direction of that dot compared to the average of all dots was determined.

To test the accuracy of the device, a Vernier caliper with a precision of $0.005 \mathrm{~mm}$ was used to measure the length between the corners of a piece of copper. The microscope was then moved to position each of the two corners at the same position as noted in the recorded image. The associated movement required was measured and compared to the actual length of the edge.

The setup of the experimental procedures was flexible due to the ability to script Franklin. To demonstrate this, two experiments were automated. First, an object with significant height was placed on the platform and images were recorded at several heights. Those images were combined into a single image with photo stacking software (Hugin, 2016). Second, a large flat object was placed on the platform and images were recorded at different horizontal positions with some overlap. Those images were combined into a single image with photo stitching software Fiji, which is imageJ with many plugins pre-configured (Fiji, 2016).

The full bill of materials and SCAD files for the 3-D printed parts are released under and open source license here (OSF, 2016).

\section{Results and Discussion}

\subsection{Results}

The fully assembled instrument is shown in Figure 1, with the lead screws, anti-backlash springs, endstops and USB microscope labeled. A holder was designed in OpenSCAD (OpenSCAD, 2016) and 3-D printed as shown in Figure 2. This holder was then supplemented with ball bearings in order to accommodate a USB microscope. This capability highlights the ability to three-dimensionally print custom parts on the same machine adapted for optical microscopy.

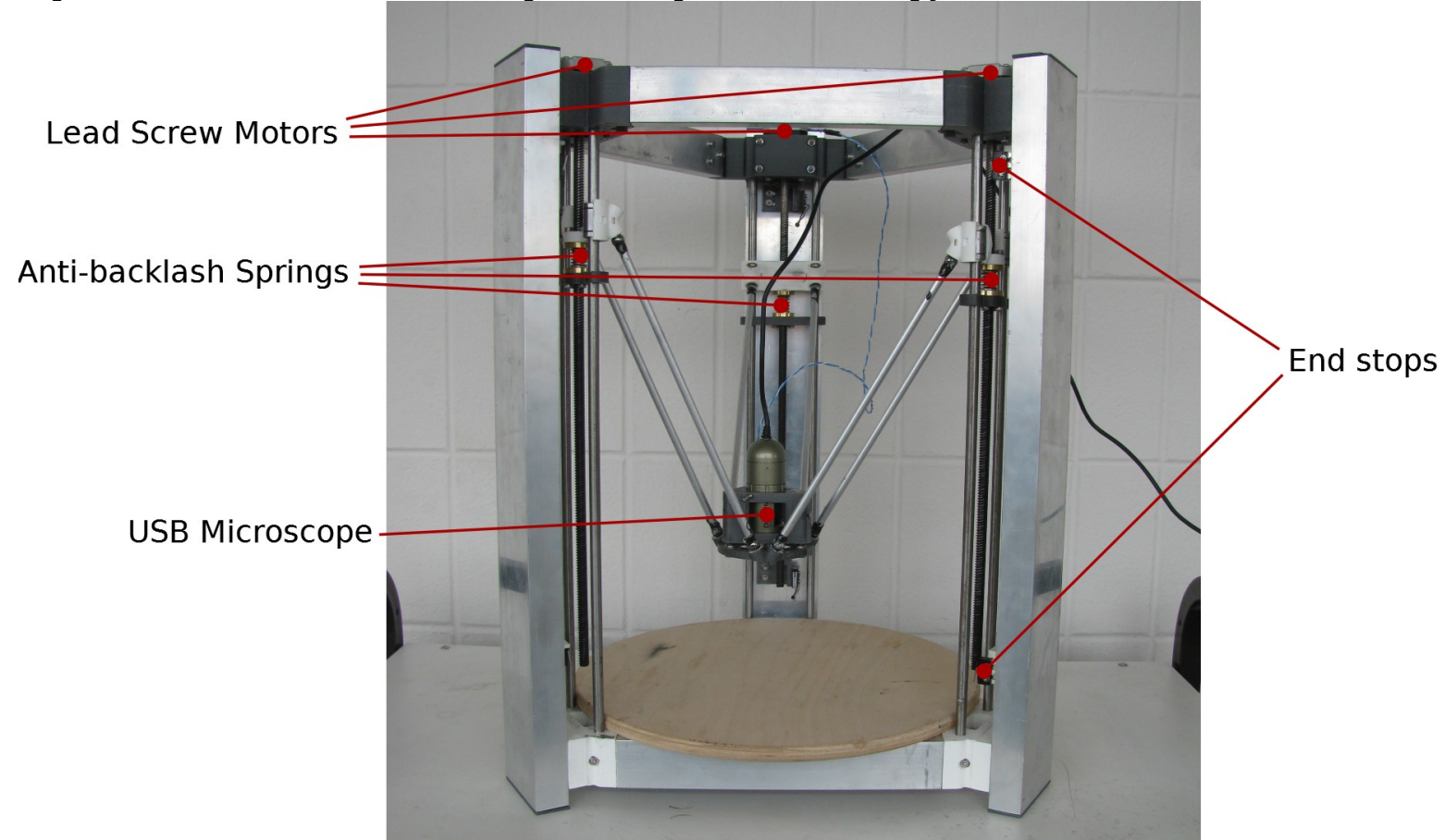

Figure 1. The open-source 3-D microscope stage with USB microscope. 

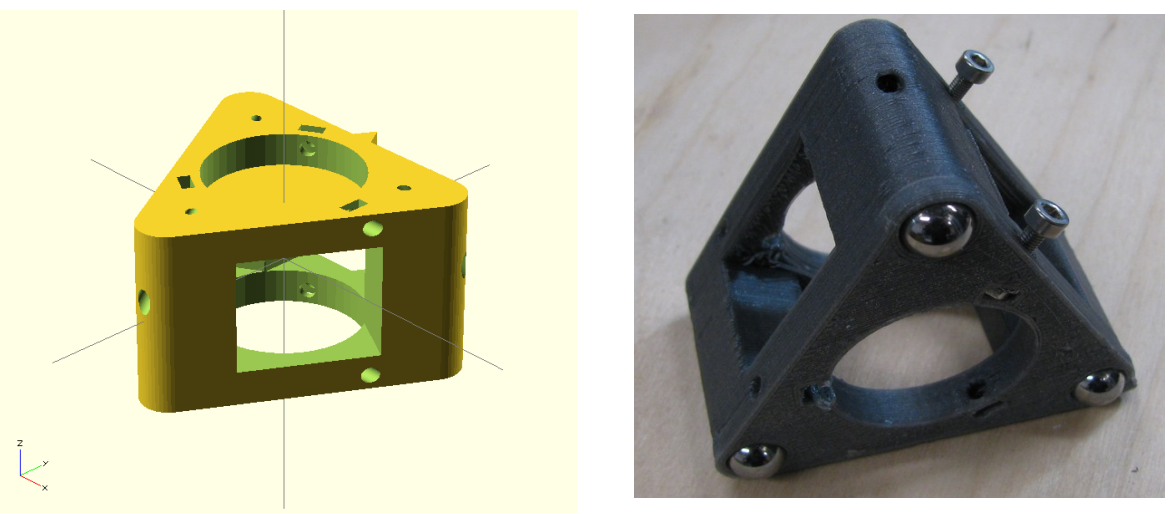

Figure 2. A) OpenSCAD STL rendering of USB microscope holder, B) Assembled USB microscope holder with ball bearings and screws.

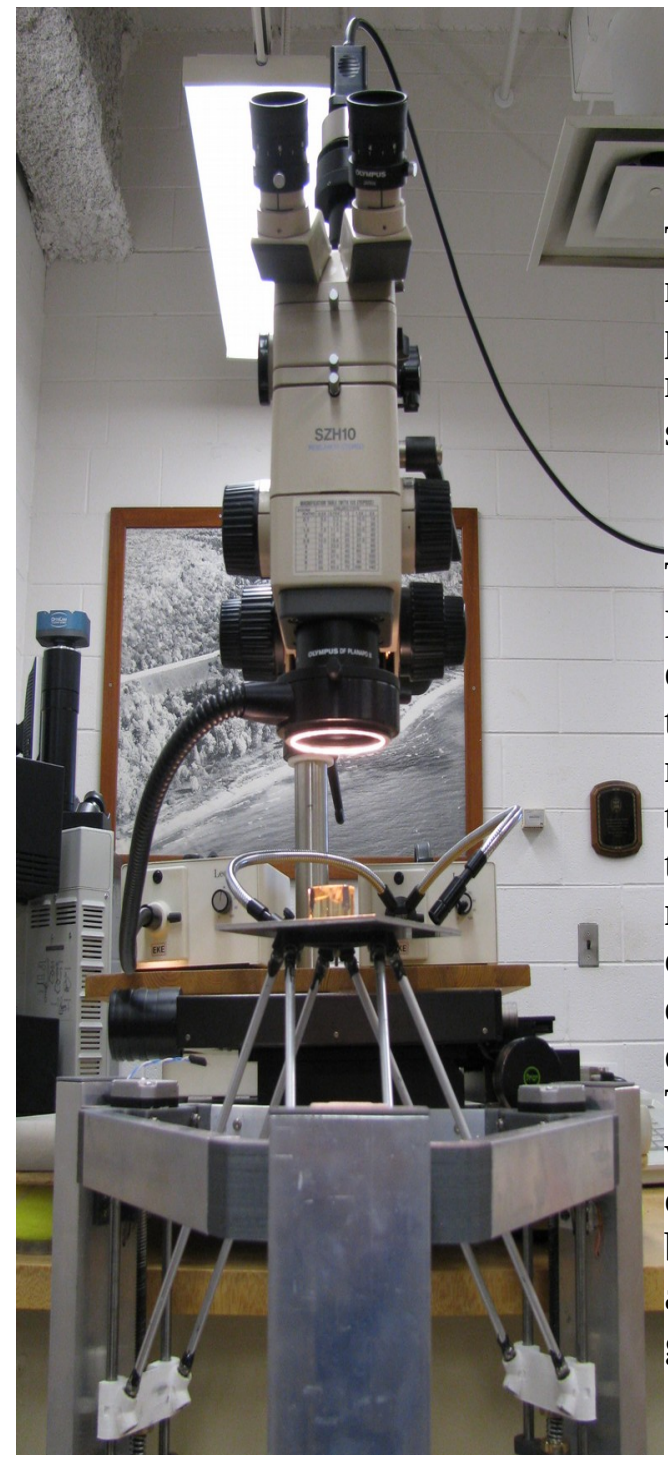

Figure 3. The 3-D microscope stage shown adapted to a stage. The stage is viewed from above by a conventional microscope.

The microscope can also work in mobile sample mode (or stage mode) by removing the tie rods from the down position and placing them in the up position on the carriages. Stage mode moves the sample underneath a conventional microscope as shown in Figure 3.

The 3-D microscope stage electronics is comprised of a Beaglebone Black and Melzi (Ardunio compatible) board. The electronic schematic for the system is shown in Figure 4. The three stepper motors that create the movement of the 3-D microscope are controlled by the Melzi, which is itself run by the Beaglebone Black. A computer is used to directly control the USB camera. This computers is also connected via the network to the Beaglebone Black. The machine is similar to the open-source multi-material additive and subtractive MOST delta RepRap (Anzalone et al., 2015) and the more advanced open source derivative called the Athena (Athena Build, 2016). The main differences between this machine and those are that wood support is replaced by aluminum tubing and that the carriages are not moved by belts, but by lead screws with antibacklash nuts. Detailed build instructions for the Athena are available on-line (Athena Build, 2016) and can be used as a guideline for building this machine.

The 3-D microscope movement is controlled by Franklin, the interface of which is shown in Figure 5. It runs on the Melzi and the Beaglebone, and is accessed through a web browser. In the top left is a list of available G-Code to execute. Below that are the controls for moving the microscope. In the top right are control buttons and below that is a graph for all the temperature sensors; that is used when Franklin 
is controlling a 3-D printer. For the microscope, this graph is empty. All setup, configuration and calibration is also performed from this interface.

Photostacking while moving the microscope in the $\mathrm{z}$ plane is demonstrated in Figure 6, where Figure 6 a shows a flower with the bottom in focus and $6 \mathrm{~b}$ with the top in focus. These were part of a stack of 10 images. Figure 6c shows the final image of the stacking technique results in an image of greater depth than any of the original images. The result is thereby of greater value to the researcher.

Figure 4. The electronic schematic of the 3-D microscope.

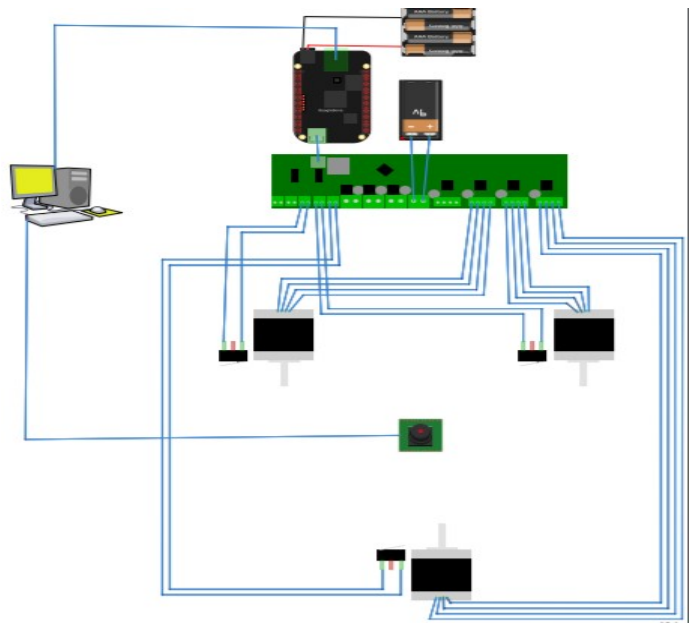

Figure 5. The Franklin interface allows users to control the movement of the USB microscope in $\mathrm{x}, \mathrm{y}$ and $\mathrm{z}$ directions.

Furthermore, G-Code files can be uploaded and executed.
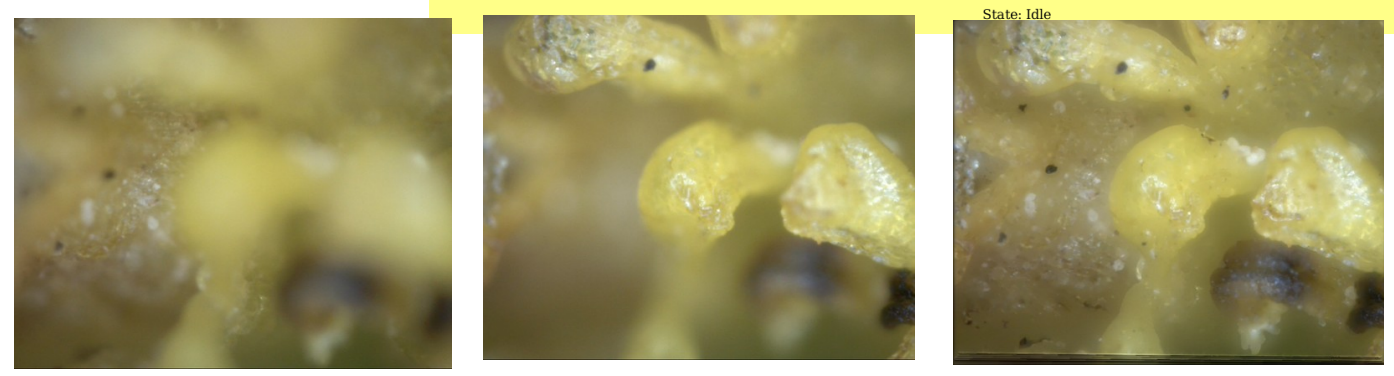

Figure 6a. An image of a flower where the bottom is in focus.

Figure 6b. An image of a flower where the top is in focus.

Figure 6c. The final image of the stacking technique results in an image of greater depth than any of the original images. 
Figure 7 demonstrates photostitching 18 individual images while moving the microscope in the $x-y$ plane on a composite paint. The techniques demonstrated in Figure 6 and 7 can be combined to image large 3-D objects with significant depth.

Figure 7. Final photostitched image of complex aggregate paint.

The precision of the instrument was found to be dependent on the speed of movement. At the maximum speed of $60 \mathrm{~mm} / \mathrm{s}$, an average error of $10 \mu \mathrm{m}$ was found. At the lowest measured speed of $2 \mathrm{~mm} / \mathrm{s}$, this average error was determined to be 27 $\mu \mathrm{m}$. This error is likely due to the lagging of components. At higher speeds, a sudden stop in movement presses the parts into their final position, resulting in a smaller positioning error. This conclusion was confirmed by the results of the small circles experiment that demonstrated that the actual position was slightly behind that of the target, resulting in a circle of smaller radius than instructed.

In measuring the accuracy of the device, a piece of copper was initially measured to be $101.22 \mathrm{~mm}$ long. The microscope measured a length of $101.64 \mathrm{~mm}$, yielding an error of $0.15 \%$. It

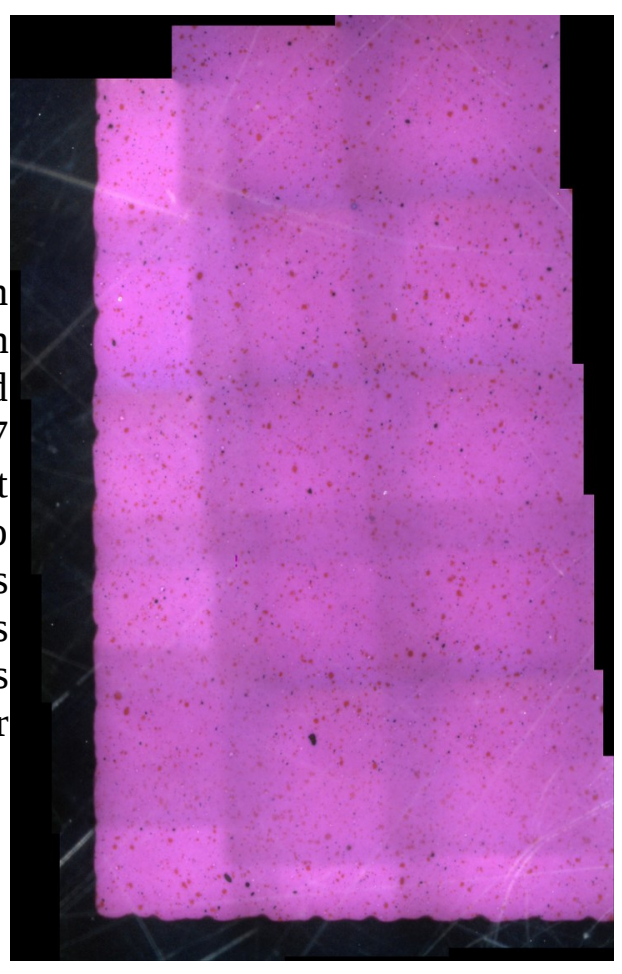
should be noted, however, that no attempt was made to calibrate the machine for scale. The absolute error at long distances can be made just as small as the error associated with precision if a calibration is performed.

Most commercially available microscope stages for scientific applications are two-dimensional. They cost around $\$ 10,000$, have a repeatability between 0.2 and $2 \mu \mathrm{m}$, and they have a precision between 5 and $500 \mathrm{~nm}$. The device presented here is three-dimensional, costs less than $\$ 1,000$, and it has a repeatability of $156 \mu \mathrm{m}$ and a precision of less than $30 \mu \mathrm{m}$. While commercial alternatives demonstrate superior operative standards, the experimental operations outlined here prove this new system to be sufficient for many scientific applications. The economic analysis of a proprietary machine compared to the OS variant described is summarized in Table 1. 
Table 1. Comparison of open source microscope to proprietary microscope specifications

\begin{tabular}{|c|c|c|c|c|c|}
\hline $\begin{array}{c}\text { Microscope } \\
\text { Stage Name }\end{array}$ & $\begin{array}{c}\text { Price } \\
\text { (USD) }\end{array}$ & $\begin{array}{c}\text { Travel } \\
\text { Range }(\mathbf{m m})\end{array}$ & $\begin{array}{c}\text { Maximum } \\
\text { Speed Limit } \\
(\mathbf{m m} / \mathbf{s})\end{array}$ & $\begin{array}{c}\text { Repeatabilit } \\
\mathbf{y}(\boldsymbol{\mu m})\end{array}$ & Reference \\
\hline $\begin{array}{c}\text { MOST Open } \\
\text { Source Stage }\end{array}$ & $\begin{array}{c}\$ 384.37 \text { 3-D } \\
\text { stage and holder }\end{array}$ & $250 \times 200$ & 40 & 156 & This study. \\
\hline $\begin{array}{c}\text { MS-9400 XY } \\
\text { Automated } \\
\text { Stage }\end{array}$ & $\begin{array}{c}\$ 925.00 \\
\text { (requires } \\
\text { controller, slide } \\
\text { inserts, spacers: } \\
\$ 5220.00)\end{array}$ & $225 \times 100$ & 7 & $<0.7$ & $\begin{array}{c}\text { (Applied } \\
\text { Scientific, } \\
\text { 2016) }\end{array}$ \\
\hline $\begin{array}{c}\text { MLS203-1 } \\
\text { XY Stage }\end{array}$ & $\begin{array}{c}\$ 6799.00 \\
\text { (Requires a } \\
\text { controller: } \\
\$ 2959.28)\end{array}$ & $100 \times 75$ & 250 & 0.25 & $\begin{array}{c}\text { (ThorLabs, } \\
\text { 2013) }\end{array}$ \\
\hline $\begin{array}{c}\text { Motorized } \\
\text { XY }\end{array}$ & $\begin{array}{l}\$ 4900.00 \\
\text { Microscope } \\
\text { Stage }\end{array}$ & $100 \times 120$ & 85 & 2 & (Zaber, 2016) \\
\hline $\begin{array}{c}\text { Leica } \\
\text { LMT260 XY } \\
\text { Scanning } \\
\text { Stage }\end{array}$ & $\$ 16,000$ & $120 \times 80$ & 500 & 0.25 & (Leica, 2016) \\
\hline
\end{tabular}

\subsection{Discussion}

It should be pointed out here that the open microscope stage is a true 3-D stage. This is extremely rare for commercial stages as manufacturers expect the microscope to move in the $\mathrm{Z}$ direction, although this is not always an option. Because of this, there were no true commercially comparable equivalent products found on the market. Despite this limitation for comparison, there are several points that are clear from Table 1. First, the open-source microscope stage is larger than all commercial tools in the survey of proprietary equipment. The size of the open source stage was largely dictated by the size of the MOST delta from which it was derived. This obviously has clear advantages for imaging large objects with complex and large variations in geometries. These types of objects are simply not generally available for microscopic imaging without disassembly or destruction (e.g. via mechanical slicing). Combining the demonstrated functionalities of the stage for both focus stacking (Figure 6) and image stitching (Figure 7), this device makes it possible for the first time to develop large composite images of the exterior of objects with enormous depth over a volume of cylinder measuring $250 \mathrm{~mm}$ in diameter by $200 \mathrm{~mm}$ in height. Future work could improve the usability of this tool by automating the focus for such stack-stitched images.

The costs of the open source stage are also at least an order of magnitude less than the proprietary commercial tools with even remotely similar functionality. The maximum speed of the open source stage is slower than the majority of tools, but is not the lowest as seen in Table 1 . Speed may become important for large dynamic image capture. Finally, the repeatability, which was measured in this study to be over 150 microns was significantly higher than all the commercial devices. For the vast majority of microscopy applications this is not a problem as the user has visual feedback (e.g. the feature of 
interest is in the field of view). The one application, where a small error in repeatability is necessary is when doing photostitching with no overlap after performing a raster over a large area. As this study has demonstrated in Fig. 7, use of open source photostitching software is an adequate solution as long as a small overlap is tolerated. The slightly slower resultant image taking time would only be a problem in experiments where the sample exhibits significant changes during the measurement, but such experiments are unsuitable for using photostitching without overlap as well.

For those needing improved repeatability the precision of the open source stage can be improved using several approaches including decreasing the volume and using larger linear bearings to decrease unwanted movement in the carriages. In addition, higher pitch lead screws would lead to smaller steps which can be useful for high magnification work.

The work presented in this paper adds to the growing interest in open source tools for microscopy (Zhang et al., 2013; Barber et al., 2013; Sharkey et al., 2015; University of Cambridge, 2016; Warwick, 2016) demonstrates a variety of similarities to the open source microscope found on OpenLab Tools (University of Cambridge, 2016). However, where that team aims to build a new machine entirely, this work targets currently existing and operational machines (ASR Series, 2016). The benefit to this approach is that it negates the necessity of a new machine, and it expands the current applications of existent lab facilities. This limits the options for the optics that can be used in mobile tool mode compared to other microscopes, including the OpenLabTools open source microscope. This limit can be avoided when using the machine in stage mode, but this limits the sample size.

This work opens the door to a multitude of potential future research investigations. The machine presented in this paper currently does not support Micro-Manager, a popular program for controlling microscopes in scientific experiments. Adding this functionality would further broaden the platform for open-source technology. Additional work could also be done in the area of calibration. As this system currently stands, calibration requires the user to understand the associated underlying processes. A separate calibration interface could be designed in order to automate and simplify calibration.

Finally, it should be pointed out that the extreme affordability of this automated 3-D microscope vastly improves accessibility. Few research groups, particularly in the developing world can afford more than $\$ 10,000$ for an automated microscope stage. This stage fits into the established paradigm of 3-D printing reducing research costs (Birtchnell \& Hoyle, 2014). By enabling more scientists to have access to cutting edge tools such as this microscope, the number and diversity of the scientific community is expected to increase (Pearce, 2014).

\section{Conclusions}

This paper presents a low-cost, open source microscope that maintains the use of the 3-D printer architecture on which the hardware is built. The machine is a true 3-D stage and thus able to operate with USB microscopes or conventional desktop microscopes. It is larger than all commercial 
alternatives, and is thus capable of high depth images over unprecedented areas and complex geometries. The repeatibility is below 2-D microscope stages, but testing shows that it is adequate for many scientific applications. The precision of the instrument was found to be dependent on the speed of movement (i.e. an average error of $10 \mu \mathrm{m}, 60 \mathrm{~mm} / \mathrm{s}$ and $27 \mu \mathrm{m}$ at $2 \mathrm{~mm} / \mathrm{s}$ ) and accuracy tests yielded an error of $0.15 \%$. The open source microscope stage costs less than $9 \%$ of the closest proprietary commercial stages. This extreme affordability vastly improves accessibility for 3-D microscopy throughout the world.

\section{Acknowledgments}

The authors would like to acknowledge technical support from G. C. Anzalone and 3D4Edu, LLC for equipment.

\section{References}

Anzalone, G.C., Glover, A., Pearce, J. (2013a) Open-Source Colorimeter. Sensors. 13 (4), 5338-5346.

Anzalone, G.C., Zhang, C., Wijnen, B., Sanders, P.G., Pearce, J.M. (2013b) A low-cost open-source metal 3-D printer. Access, IEEE. 1, 803-810.

Anzalone, G.C., Wijnen, B., Pearce, J.M. (2015) Multi-material additive and subtractive prosumer digital fabrication with a free and open-source convertible delta RepRap 3-D printer. Rapid Prototyping Journal. 21(5), 506-519.

Applied Scientific. (2016) MS-9400 XY Automated Stage. Retrieved from http://www.asiimaging.com/index.php/products/stages/upright-stages/ms-9400-xy-automatedstage/\#tab-id-2.

Athena Build Overview. (2016) Retrieved from http://www.appropedia.org/Athena_Build_Overview.

Baden, T., Chagas, A.M., Gage, G., Marzullo, T., Prieto-Godino, L.L., Euler, T. (2015) Open labware: 3-D printing your own lab equipment. PLoS Biol. 13 (3), e1002086.

Barber, P.R., Tullis, L.D.C., Pierce, G.P., Newman, R.G., Prentice, J., Rowley, M.I., Matthew, D.R.,

Ameer-Beq, S.M., Vojnovic, B. (2013) The Gray Institute 'open' high-content, fluorescence lifetime microscopes. Journal of Microscopy, 25(2), 154-167.

Birtchnell, T., Hoyle, W. (2014) 3D Printing for Development in the Global South: The 3D4D Challenge. Palgrave Macmillian.

Riedl, J.A., Stouten, K., Ceelie, H., Boonstra, J., Levin, M.D. and van Gelder, W. (2015) Interlaboratory reproducibility of blood morphology using the digital microscope. Journal of Laboratory Automation. 20(6), 670-675.

Borgen, E., Naume, B., Nesland, J.M., Nowels, K.W., Pavlak, N., Ravkin, I. and Goldbard, S., (2001) Use of automated microscopy for the detection of disseminated tumor cells in bone marrow samples. Cytometry, 46(4), 215-221.

Bowyer, A. (2013) 3D printing and humanity's first imperfect replicator. 3D Printing and Additive

Carro, A., Perez-Martinez, M., Soriano, J., Pisano, D.G. and Megias, D., 2015. iMSRC: converting a standard automated microscope into an intelligent screening platform. Scientific Reports, 5. Article number: 10502. DOI: 10.1038/srep10502

Carvalho, M.C.; Eyre, B.D. A low cost, easy to build, portable, and universal autosampler for liquids. Methods in Oceanography 8, 23-32.

Cybulski, J. S., Clements, J., Prakash, M. (2014) Foldscope: origami-based paper microscope.,” PLoS One. 9,(6) e98781.

D’Ambrosio, M.V., Bakalar, M., Bennuru, S., Reber, C., Skandarajah, A., Nilsson, L., Switz, N., Kamgno, J., Pion, S., Boussinesq, M. and Nutman, T.B. (2015) Point-of-care quantification of 
blood-borne filarial parasites with a mobile phone microscope. Science Translational Medicine, 7(286), 286re4.

Da Costa, E.T., Mora, M.F., Willis, P.A., do Lago, C.L., Jiao, H., Garcia, C.D. (2014) Getting started with open-hardware: development and control of microfluidic devices. Electrophoresis. 35 (16), 2370-2377.

Damase, T. R., Stephens, D., Spencer, A., Allen, P. B. (2015) Open source and DIY hardware for DNA nanotechnology labs. J. Biol. Methods. 2 (3), e24.

Fiji. (2016) http://fiji.sc/Fiji

Franklin. (2016) 3D printer controlling software. GitHub. 2015. https://github.com/mtu-most/franklin/

Gross, B. C., Erkal, J. L., Lockwood, S. Y., Chen, C., Spence, D. M. (2014) Evaluation of 3D printing and its potential impact on biotechnology and the chemical sciences. Anal. Chem. 86 (7), 32403253.

Hermann, K.-H., Gärtner, C., Güllmar, D., Krämer, M., Reichenbach, J. R. (2014) 3D printing of MRI compatible components: why every MRI research group should have a low-budget 3D printer. Med. Eng. Phys. 36(10): 1373-1380.

Holdaway, C.A. (2004) Automation of pollen analysis using a computer microscope. Master's Thesis, Massey University.

Hugin. (2016) Retrieved from http://hugin.sf.net

Irwin, J.L., Pearce, J.M., Anzolone, G., Oppliger, D.E. (2014) The RepRap 3-D printer revolution in STEM education. In 121st ASEE Annual Conference \& Exposition. Indianapolis, IN, USA, June 15-18, 2014, Paper ID \#8696

Jones, R., Haufe, P., Sells, E. (2001) Reprap - The self-replicating rapid prototyper. Robotica. 29(1), 177-191.

Kelley, C. D., Krolick, A., Brunner, L., Burklund, A., Kahn, D., Ball, W. P., Weber-Shirk, M. (2014) An affordable open-source turbidimeter. Sensors. 14 (4), 7142-7155.

Kogut, B., Metiu, A. (2001) Open source software development and distributed innovation. Oxford Review of Economic Policy. 17, 248-264.

Lakhani, K.R., Von Hippel, E. (2003) How open source software works: "Free” user-to-user assistance. Research Policy. 6, 923-943.

Laverty, D. M., Best, R.J., Brogan, P., Al Khatib, I., Vanfretti, L., Morrow, D. J. (2013) The OpenPMU platform for open-source phasor measurements. IEEE Trans. Instrum. Meas. 62 (4), 701-709.

Leica Microsystems. (2016) Accurate and Reproducible Results Leica LMT260 XY Scanning Stage. Retrieved from http://www.leica-microsystems.com/products/stereo-microscopesmacroscopes/accessories/details/product/leica-lmt260-xy-scanning-stage/

Lücking, T. H., Sambale, F., Beutel, S., Scheper, T. (2014) 3D-printed individual labware in biosciences by rapid prototyping: In vitro biocompatibility and applications for eukaryotic cell cultures. Eng. Life Sci. 15(1), 57-64.

Malonado-Torres, M., Lopez-Hernandez, H.F., Jimenez-Sandoval, P., Winkler, R.J (2014) Proteomics. 15(1), 57-64.

Mastronarde, D.N. (2005) Automated electron microscope tomography using robust prediction of specimen movements. Journal of Structural Biology 152(1), 36-51.

Micro Manager. (2016) Micro-manager open source microscopy software. Retrieved from https://micro-manager.org/

Mockus, A., Fielding, R.T., Herbsleb, J. (2002) Two case studies of open source software and development: Apache and Mozilla. ACM Transactions on Software Engineering and Methodology. 11(3), 309-346.

OpenSCAD (2016) Retrieved from http://www.openscad.org/

OSF (2016) Open-source 3-D Platform for Scientific Instruments. Koios master.zip. Retrieved from https://osf.io/v2pwa/

Pearce, J.M. (2012) Building research equipment with free, open-source hardware. Science. 337 (6100), 1303-1304. 
Pearce, J.M. (2014a) Open-source lab: how to build your own hardware and reduce research costs. Elsevier: Amsterdam, Boston.

Pearce, J. M. (2014b) Laboratory equipment: Cut costs with open-source hardware. Nature. 505 (7485), 618.

Pearce, J. M. (2015) Quantifying the Value of Open Source Hardware Development. Mod. Econ. 06 (01), 1-11.

Pearce, J. M. (2016) Return on Investment for Open Source Hardware Development. Sci. Public Policy.. DOI :10.1093/scipol/scv034

Raymond, E. (1999) The cathedral and the bazaar. Knowledge, Technology \& Policy. 12(3), 23-49.

Rundle, G. (2014) A Revolution in the Making: 3D Printing, Robots and the Future. Affirm Press.

Schindelin, J., Rueden, C.T., Hiner, M.C. and Eliceiri, K.W., (2015). The ImageJ ecosystem: An open platform for biomedical image analysis. Molecular reproduction and development, 82(7-8), 518-529.

Schneider, B., Vanmeerbeeck, G., Stahl, R., Lagae, L., Dambre, J. and Bienstman, P., (2015), July. Neural network for blood cell classification in a holographic microscopy system. In Transparent Optical Networks (ICTON), 2015 17th International Conference on (pp. 1-4). IEEE.

Sells, E., Bailard, S., Smith, Z., Bowyer, A., Olliver, V. (2010) The replicating rapid protoypermaximizing customizability by breeding the means of production. Handbook of Research in Mass Customization and Personalization. Vol 1. World Scientific: New Jersey. (568-580).

Sharkey, J.P., Foo, D.C.W., Kabla, A., Baumberg, J.J., Bowman, R.W. (2015) A one-piece 3D printed microscope and flexure translation stage. arXiv:1509.05394.

Soderberg, J. (2008) Hacking Capitalism: The Free and Open Source Software Movement. Routledge.

Su, C.-K., Hsia, S.-C., Sun, Y.C. (2014) Three-dimensional printed sample load/inject valves enabling online monitoring of extracellular calcium and zinc ions in living rat brains. Anal. Chim. Acta 838, 58-63.

ThorLabs. (2016) High-Speed Motorized XY Scanning Stages. Retrieved from http://www.thorlabs.com/newgrouppage9.cfm?objectgroup_id=5360. 2013

University of Cambridge. (2016) The open microscope. Retrieved from http://openlabtools.eng.cam.ac.uk/Instruments/Microscope/.

Vaughan-Nichols, S.J. (2014) Linux dominates supercomputers as never before. ZDnet. Retrieved from http://www.zdnet.com/article/linux-dominates-supercomputers-as-never-before/

Warwick (2016) Warwick Open Source Microscope. Retrieved from http://wosmic.org/

Weber, S. (2004) The Success of Open Source. Vol 897. Harvard University Press: Cambridge, MA, USA.

Wijnen, B., Anzalone, G. C., Pearce, J. M. (2014) Open-source mobile water quality testing platform. Water Sanit. Hyg. Dev. 4 (3), 532-537.

Wijnen, B., Anzalone, G. C., Haselhuhn, A.S., Sanders, P.G., Pearce, J. M. (2016) Free and Opensource Control Software for 3-D Motion and Processing. Journal of Open Research Software, 4: e2, DOI: $10.5334 /$ jors.78

Wittbrodt, J. N., Liebel, U., Gehrig, J. (2014) Generation of orientation tools for automated zebrafish screening assays using desktop 3D printing. BMC Biotechnol. 14 (1), 36.

Woelfe, M., Olliaro, P., Todd, M. H. (2011) Open science is a research accelerator. Nat. Chem. 3 (10), 745-748.

Zaber. (2016) ASR Series: Motorized XY Microscope Stages.

Zhang, C., Anzalone, N. C., Faria, R. P., Pearce, J. M. (2013) Open-source 3D-printable optics equipment. PLOS ONE. 8 (3), e59840.

Zhang, C. Wijnen, B. and Pearce. J.M. (2016) Open-source 3-D Platform for Low-cost Scientific Instrument Ecosystem. Journal of Laboratory Automation. DOI: 10.1177/2211068215624406 